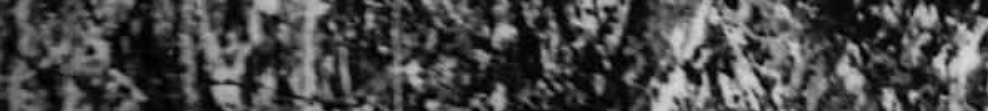
1.

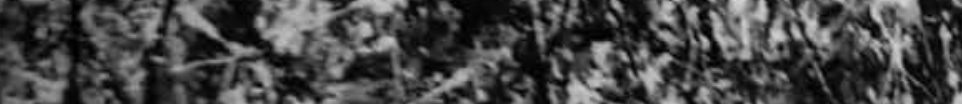

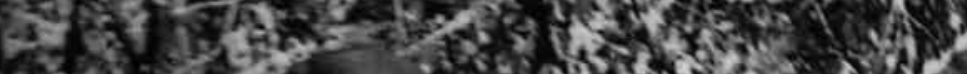

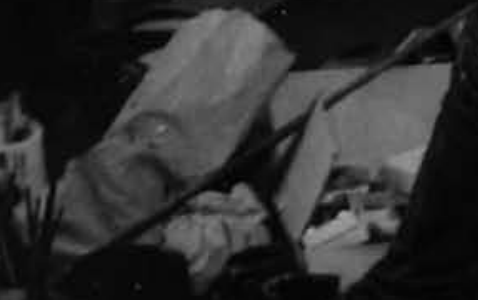

anderans (f) 2 is 3t? 130

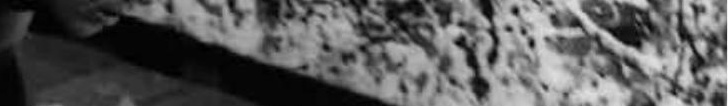
$\frac{1}{4}$

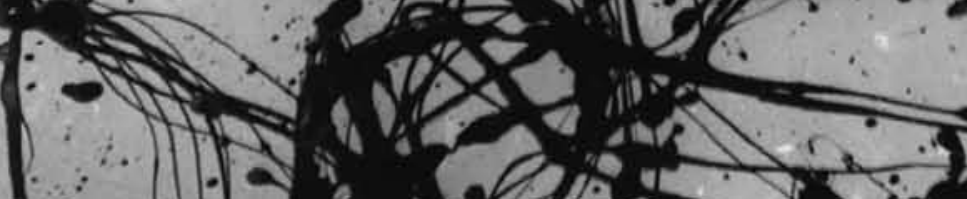




\section{Luiz Renato Martins ECONOMIA POLÍTICA \\ da arte moderna/ providências para uma história crítica}

Este texto, a ser publicado em duas partes, contém, com pequenas modificações para efeito de edição, extratos da introdução e da conclusão da tese de doutorado A fabricação da pintura: de Manet a Rothko, defendida no Departamento de Filosofia, FFLCH-USP, sob orientação do Prof. Dr. Paulo Arantes em $2000^{1}$.

Opondo-se à visão hegemônica propagada pelas correntes formalistas, cujas motivações ideológicas pretende explicitar, o ensaio salienta a valorização dos processos produtivos frente às obras acabadas como característica fundamental da arte moderna, característica por meio da qual os artistas resistem ao progresso da modernização capitalista.

palavras-chave: arte como processo; formalismo; arte moderna; modernização

O objeto deste estudo é, em primeiro lugar, a produção material.

K. Marx, [Introdução] Para a crítica da economia política ${ }^{2}$

\section{Quatro teses para a crítica do formalismo}

1. A arte moderna (que surgiu, segundo Baudelaire [1821-1867], com a obra republicano-revolucionária de Jacques-Louis David [1748-1825] realizada entre 1791 e 1794) firmou-se em meados do século XIX como desdobramento cultural dos valores da Revolução Francesa, contraditados pela reação conservadora que cobriu toda a Europa antes e após a intensa onda revolucionária de 1848.

2. A arte de vanguarda não foi de vanguarda, mas, para usar uma expressão tardia de Mário Pedrosa (1900-1981)³ , de retaguarda e resistência, ou seja, consistiu numa forma de guerrilha simbólica contra o progresso da modernização capitalista.

3. O formalismo, que elaborou a visão mais aceita e difundida da arte moderna, constituiu uma perspectiva associada e própria de apenas algumas das tendências do modernismo, especificamente do impressionismo e do simbolismo pós-impressionista, e veiculou assim os valores próprios dessas correntes, segundo a ideologia da "opticalidade" - ou da "école des yeux" (escola dos olhos), como então se dizia na França - conforme doutrina que consistia num derivado atualizado e sumário do neoplatonismo antigo. Portanto o formalismo nunca pôde dar conta dos princípios e das fronteiras constitutivos da arte moderna como um todo.

4. Um dos pontos cegos do formalismo - cujos princípios supõem a positivação e a reificação ou a absolutização da noção de obra de arte, como ser dotado de razão própria, de completude e auto-suficiência - consiste precisamente na dificuldade deste em assimilar, como uma das características fundamentais da arte moderna, a
1. Daí seu caráter fragmentário e suas referências freqüentes a um texto maior que é o da tese referida. A primeira parte, ora publicada, foi extraída da introdução. Será seguida, assim espero, no próximo número de Ars, pela parte correspondente à conclusão. Entre as modificações em relação ao texto original, constam as do título e intertítulos e da epígrafe, específicos da presente publicação.

2. Essa introdução, que ficou inédita, precede possivelmente os apontamentos de Marx entre os anos de 1857-8. Segundo José Arthur Giannotti e Edgar Malagodi, "foi descoberta em 1902 entre os manuscritos deixados por Marx, e publicada pela primeira vez por Kautsky, na revista Die Neue Zeit em 1903. É a esta Introdução que Marx faz alusão em seu prefácio de Para a crítica da economia política. O título 'Introdução à crítica da economia política' não é do seu próprio autor, mas refere-se ao nome com que foi publicada pela primeira vez e que se tornou tradicional". Cf. GIANNOTTI, José Arthur; MALAGODI, Edgar. Nota 1. Para a crítica da economia política. In: MARX,

Karl. Manuscritos 
econômico-filosóficos e outros textos escolhidos. Sel. de textos de J. A. Giannotti, trad. de J. C. Bruni et al. São Paulo: Nova Cultural, 1987, p. 3. (Coleção Os pensadores).

3. Ver PEDROSA, Mário. Variações sem tema ou a arte da retaguarda. In: Política das artes/ Mário Pedrosa: textos escolhidos I. Org. e apres. Otília Arantes. São Paulo: Edusp, 1995, p. 341-7. dissolução do valor da obra acabada, correlata à primazia dos processos produtivos frente aos resultados.

Em poucas palavras, tais são algumas das idéias e das linhas de investigação desenvolvidas pelo estudo cuja introdução se segue.

\section{Introdução:}

Providências gerais e pontuais para a construção de uma investigação sobre a arte como processo produtivo

\section{(Situar historicamente)}

A razão da ênfase do artista moderno nos processos produtivos, em detrimento da obra acabada, é o fato de que o processo geral de modernização, fundado no sistema capitalista de produção de mercadorias, traz entre outras conseqüências a rápida caducidade de todo valor e forma social de relação, o que no campo específico da arte se traduz na necessidade constante de renovação das formas de criação de valor artístico diante do precoce envelhecimento das fórmulas de valoração e significação precedentes.

\section{(Focar o estudo no processo de produção)}

O inacabamento, o modelado sumário, a produção simultânea de várias obras ou a multiplicação das versões, como variantes de um mesmo processo, e a rapidez de execução põem-se assim como distintas maneiras por meio das quais os artistas modernos buscaram estabelecer a primazia da produção sobre a forma final, a fim de prevenir e remediar o esvaziamento e o envelhecimento, cada vez mais rápidos, dos seus materiais e modos de trabalho.

Decerto, não se supõe que seja esta uma característica singular e exclusiva da arte moderna senão na intensidade e no grau de aceleração, que nesta última caracterizaram crescentemente a fadiga e o perecer das matérias, modos e valores. Assim, a importância histórica que vários dos estudos de Giulio Carlo Argan (1909-1992) atribuem ao maneirismo do século XVI, e especialmente aos non-finiti de Michelangelo (1475-1564), Ticiano (1490-1576) e Palladio (1508-1580)-neles estabelecendo o novo estatuto simbólico adquirido pela práxis artística -, salienta a etapa inicial do processo de valorização do momento produtivo em detrimento daquele da obra acabada.

Em conexão com a valorização do processo de produção em contraposição àquele de contemplação, os estudos de Argan sobre a arquitetura e a arte barrocas, em L'Europa delle capitali (1964) e outros ensaios, subvertem e explicitam - ao destacarem o caráter marcadamente "interessado" e urbanisticamente planejado da produção artística do século XVII em diante - o teor ideológico do discurso estético que se aglutinará no século seguinte em torno da idéia de contemplação, no nascer da "estética" como disciplina ou ciência da contemplação do belo. 
Assim, a decisão de priorizar o exame da produção, tomada por Walter Benjamin (1892-1940), Argan e outros, constitui um ato de estratégia crítica em face de uma tendência ideológica, historicamente dominante; tendência esta, claramente pró-capitalista, que tem o propósito, no campo da arte como nos demais, de estabelecer, independentemente das questões da produção, os critérios da contemplação ou da consideração exclusiva da moeda da forma, em toda e qualquer realização humana.

\section{(Reconhecer e periodizar a hegemonia histórica da grande narrativa formalista)}

É necessário, para uma construção crítica da história da arte moderna, confrontar-se com juízos e princípios da corrente crítico-historiográfica denominada formalista e da doutrina estética a ela inter-relacionada: a teoria da "pura visibilidade". Apoiadas na idéia de contemplação, ambas elaboraram a visão mais influente e difundida das artes plásticas entre o final do século XIX e a maior parte do século XX, período abordado por esta investigação.

Apesar de se apresentarem ao longo do século XX visões críticas de exceção - como as de Benjamin, Argan, Pierre Francastel (1905-1970), T. J. Clark (1943-) e outras em diálogo com o materialismo histórico - e, ainda, de surgirem, mais recentemente, desde os idos de 1980, críticas ecléticas contra o formalismo - como a dos "estudos culturais" no bojo do difuso conjunto de posições chamadas de pós-modernistas -, é necessário reconhecer que o formalismo continua a ser, em razão de sua ampla e longeva hegemonia no século XX, e dado o volume, a seriedade e argúcia das suas interpretações, senão o paradigma historiográfico ainda o mais influente, certamente, a referência incontornável em se tratando da "grande narrativa" ou da história das artes visuais modernas como um todo.

Noutras palavras, para além dos méritos individuais de seus artífices ou de seus opositores, é uma questão de fato, ou seja, de juízo histórico e de uma periodização racional dos ciclos de idéias, reconhecer que o formalismo constituiu certa leitura ou narrativa da arte moderna, cuja coerência se impôs internacionalmente a um amplo número de estudiosos, que, com ressalvas pontuais, a ela se referem, aceitando-lhe o nexo essencial.

De outro lado, por mais significativas e inovadoras que tenham sido, no campo da arte moderna, as pesquisas específicas empreendidas por estudiosos de extração não-formalista, como Argan, Francastel e Leo Steinberg (1920-), ou, mais esporadicamente, os de matriz iconológica ou warburguiana, cuja inclinação é mais afeita à arte antiga, como Panofsky (1892-1968), Chastel (1912-1990) e Gombrich (1909-2001), dificilmente os seus resultados lograram, do ponto de vista da influência ${ }^{4}$, ultrapassar certos limites ou o teor de estudos pontuais, para consolidar efetivamente uma outra narrativa da arte moderna.

Já o formalismo, originariamente de expressão alemã e vienense, deitou sólidas raízes a partir do final do século XIX e do início do XX no meio cultural anglo-

\footnotetext{
4. Para não perder o fio, deixo de referir aqui uma série de autores não-formalistas de gerações mais recentes, cujos
} 
trabalhos são objeto de discussão ou aplicação no curso da tese referida. Nesta passagem, é o caso de indicar, apenas, ou obras já completas ou com fisionomia já plenamente definida, como a de Leo Steinberg.

5. Para efeito de definição e a título de síntese, a noção de realismo que é compatível com o pensamento de Argan e, de resto, também com o de Brecht, e com a qual se irá trabalhar aqui, foi bem precisada em 1923 por

Tarabukin: "Eu uso o conceito de realismo no seu sentido mais amplo e não de modo algum identificado com o naturalismo, que é uma das formas de realismo e, nessa condição, uma das mais primitivas $\mathrm{e}$ americano, e conquistou apoios de monta em vários outros círculos, inclusive, hoje, na França e nos EUA, onde se verificaram hibridizações do formalismoà base do neo-estruturalismo. O composto resultante encontra atualmente grande aceitação nos EUA. Trata-se portanto de uma espécie de língua franca internacional, no que concerne à história e à crítica da arte moderna.

Logo, em vista deste debate, que é incontornável para a reabertura da discussão sobre a formação do processo artístico e estético moderno, adquire valor estratégico o reexame daquelas teses que se tornaram os esteios principais da concepção formalista da arte moderna, a saber: a visão de Manet (1832-1883) como origem da arte moderna e pintor precursor do impressionismo, segundo a doutrina opticalista; as teses acerca de Cézanne (1839-1906) como paradigma "clássico" do modernismo e, correlatamente, do cubismo como estilo fundamentalmente abstrato.

Por fim, a desmontagem crítica do dispositivo historiográfico formalista, que foi incorporado pelas instituições norte-americanas, deverá rematar com a abordagem, na presente investigação, de um tópico decisivo na história da ascensão da arte norte-americana: a discussão do expressionismo abstrato, posto pelo formalismo como corolário do processo histórico da arte moderna.

\section{(O partido do realismo)}

Não se buscará negar a importância marcante do trabalho dos artistas em questão, mas de reabrir a interpretação de suas obras, e reinscrevê-las em situações e partidos históricos muito diversos daqueles apontados pela historiografia formalista. À diferença da orientação desta última, o partido investigativo aqui adotado, de acordo com Argan, destaca o realismo como o principal fio condutor da arte moderna, observando sucessivamente, nos pintores cujas obras são adiante focalizadas, a saber, Manet, Monet (1840-1926), Cézanne, Van Gogh (1853-1890), Braque (1882-1963) e Picasso (1881-1973), distintas etapas e perspectivas de uma reflexão crítica cujo móvel comum consiste na atualização do realismo como explicitação dos processos produtivos ${ }^{5}$. Dessa perspectiva, as obras de Pollock (1912-1956) e Rothko (1903-1970), longe de poderem ser classificadas como abstratas, explicam-se, com mais pertinência, no âmbito próprio da crise da figuração e da dialética correlata entre figuração e abstração, desencadeada no próprio âmago do realismo, a partir do desdobramento reflexivo das suas premissas principais.

De resto, esses dois artistas norte-americanos, muito embora cientes de fazerem uma arte de crise e de se encontrarem numa situação em larga medida aporética quanto à tradição realista, nunca abandonaram o diálogo com o realismo, nem renunciaram à ambição paradoxal de uma "re-semantização", entendida como redefinição da função ou da objetivação da pintura, como discurso realista da produção, visando à sua reinserção na discussão e na reflexão de questões extrapictóricas, projetadas contra a história humana como um todo. 
(Pôr em situação)

Antes, porém, de discutir esses pontos cruciais da arte moderna, a investigação deve enfocar as primeiras décadas do século XIX, para situar historicamente os atos iniciais de um processo cultural, comandado no terreno cognitivo pela ciência que, partindo das novas investigações sobre a fisiologia, conduziu à completa reestruturação da noção de percepção e, em particular, para o que ora interessa, da idéia de olhar.

Deu-se assim entre 1810 e 1840 , um desenraizamento da visão frente a parâmetros fixos e estáveis, dissolvendo-se todo princípio racional de verossimilhança. A ruptura com a concepção clássica da visualidade, de matriz geométrica, dissolveu a idéia da visão como apreensão neutra de objetos naturais preexistentes, para em lugar disso refundar a visualidade no sujeito e numa concepção ativa da sensibilidade como instância espontaneamente produtiva. A postulação da autonomia do sujeito e a positivação do corpo como foco espontâneo de sensações acarretaram a liquidação do diálogo paradigmático entre arte e natureza, no qual se fundara a tradição artística e estética anterior.

Afastando-se, porém, dos ideais de racionalidade e emancipação do Iluminismo, a reestruturação do olhar redefinido como produção subjetiva, independente dos objetos preexistentes da visão e em vinculação com os processos fisiológicos estabelecidos pela exploração científica do corpo, ocorreu no âmbito de um corpo desnaturalizado, sujeito a estímulos artificiais e ritmos heterônomos, tais como aqueles da linha de montagem, dos novos meios de transporte e da parafernália da diversão e da informação em grande escala, que visavam a sensação num corpo parcelado e segmentado, "independentizado" ou isolado da consciência.

Nesse prisma, um modelo perceptivo, com funcionamento autônomo diante da natureza e de todo vínculo de origem, já é cogitado pela ciência e gera padrões culturais algumas décadas antes das grandes transformações que se tornarão evidentes na pintura da segunda metade do século XIX.

Os traços mais nítidos da quebra dos cânones artísticos acadêmicos, com que se costuma identificar o início do modernismo nas artes, sobrevêm décadas após as primeiras formulações das ciências positivas. Melhor seria, portanto, para dar conta desse atraso das reações artísticas, após o progresso acelerado das ciências positivas, da tecnologia e das mudanças políticas e das relações sociais que antecedem àquelas nas artes, não chamar a arte moderna de arte de vanguarda, mas de retaguarda, como observou Mário Pedrosa ${ }^{6}$. Isso tem a vantagem de tornar mais clara a razão de ser do caráter provocativo, freqüentemente assumido pela arte moderna, evidenciando que a agressão pontual e isolada contra o bloco de forças hegemônicas é própria de um processo de resistência conduzido por forças minoritárias, que golpeiam os flancos ou a retaguarda de um inimigo, a cujo avanço não podem fazer frente. Assim, por exemplo, é em termos antitéticos que a arte moderna se firma como discurso, nas críticas de Daumier (1808-1879) contra a ingênuas. A consciência estética contemporânea transferiu a idéia de realismo, do conteúdo para a forma do trabalho de arte. Doravante o motivo dos esforços realistas deixou de ser a cópia da realidade (como tinha sido para os naturalistas). [...] Nas formas da sua arte o artista cria a sua atualidade, e, para ele, o realismo é a criação de um objeto genuíno...". Cf. TARABUKIN, N.

From the easel to the machine (1923). Trad. Christina Lodder. In: FRASCINA, F;

HARRISON, C. (Org.). Modern art and modernim: a critical anthology. Nova Iorque: Icon Editions/ Harper \& Row, 1987, p. 136.

6. Ver PEDROSA. Op. cit., p. 341-7. 
monarquia de Luís-Felipe (1773-1850); de Courbet (1819-1877) e Manet contra o II Império e a república conservadora, a seguir; de Cézanne e Van Gogh contra a industrialização; do fovismo e do cubismo contra a direita chauvinista que levaria a França à guerra de 14; de Picasso e Miró (1893-1983) contra o franquismo; do expressionismo abstrato contra o teor totalitário do macarthismo e da vida administrada, nos EUA do pós-guerra. Desse modo, freqüentemente anticapitalista - ainda se só mais ocasionalmente revolucionária -, a arte moderna constituiu-se, com freqüência, numa fuga para a frente, num ato de guerrilha e de sobrevivência, numa manobra de resistência à ameaça concreta de aniquilação.

Em suma, as correntes artísticas - historicamente assentadas nos valores da maestria artesanal e herdeiras da politização desses segmentos desde a Revolução Francesa, mas tornadas anacrônicas pela nova divisão social do trabalho que se impõe com força esmagadora - ditas imprecisamente de vanguarda, ao partirem de um intuito crítico, desenvolverão uma relação antitética e crítica com a nova ordem social, o que se evidencia na estruturação de um discurso estético agressivo e provocativo.

\section{(Os novos modos do valor ou a arte como processo)}

Se a arte moderna não apresenta "obras" propriamente acabadas, mas antes processos, tal condição requer - ao contrário do elenco de procedimentos analíticos formalistas - práticas e disposições de parte do investigador, que priorizem a análise dos procedimentos produtivos. Assim, por exemplo, se a partir do impressionismo a questão serial se tornou um problema latente, já o cubismo, por sua vez, implicou que a obra, ao invés de ser analisada isoladamente, precisava ser remetida à série processual que a engendrou.

É certo que, muitas vezes, essa série não se apresenta em termos efetivos e positivos, por motivos variados. De fato, constitui prática mais tardia a disposição de expositores e de curadores de mostrar cada trabalho como parte de uma série, com as suas variações possíveis ao lado. E, antes, muitas vezes até ocorria do próprio artista, mesmo quando dispunha de variações ou formas preliminares, como no caso de Monet, ou ocultá-las e não apresentar ao público outros termos da mesma cepa, tal como os trabalhos considerados como meros esboços ou aproximações infrutíferas do tema em tela, ou não extrair maiores conseqüências de um modo de trabalho já parcialmente serial, para continuar a elaborar, ao invés, estruturas pictóricas ainda orgânicas ou unas.

Já, por outro lado, deve-se considerar que o chamado inacabamento ou modelado sumário - que acomete os trabalhos modernos, desde o início do realismo francês, vide, por exemplo, Manet e Cézanne, tão criticados à época pelo estado inacabado de suas obras - constitui um prenúncio ou sintoma inicial de um fenômeno estrutural e mais radical: o de que cada trabalho moderno é virtualmente concebido só como uma alternativa possível, entre outras, ou, noutras palavras, para emprestar a expressão de James Joyce (1882-1941), como uma "obra em progresso". 
Se o caráter serial do processo é proclamado por notas complementares, como será no caso de Duchamp (1887-1968), ou se é ou não escamoteado pelo artista, como no caso Monet, é uma outra questão, mais específica e pertinente a cada conduta autoral. De todo modo, uma das hipóteses gerais que se devem averiguar - com a qualidade de indício da valorização da produção sobre a contemplação - afirma que é quase sempre como alternativa ou variação possível, e quase nunca como solução final, que os trabalhos modernos mais marcantes e relevantes são levados a público. Das inúmeras "Sainte-Victoires" de Cézanne, passando por "Les demoiselles d'Avignon", pelas obras cubistas, pelos tantos trabalhos de Duchamp, até os trabalhos do chamado expressionismo abstrato, os casos mais significativos da arte moderna são permeados dessa espécie de fragilidade, que os constitui inevitavelmente como formas provisórias e estases momentâneas de um processo que, por outro lado, vem a ser enfatizado a partir da originalidade e radicalidade dos seus procedimentos. Logo, ao invés de produtos, salientam-se processos elaborativos e modos de produção. $\mathrm{O}$ artista não se destaca tanto pelos exemplares únicos, quanto pelos processos que concebe e realiza ou propõe. De télos ou destino final, a obra moderna se transforma assim em mero documento ou registro de um certo modo produtivo. E vem a se reestruturar, ao modo de uma "refuncionalização" ciente e por sua própria conta, numa nova ordem, a do capitalismo avançado, a cujo andamento a arte como paradigma de excelência artesanal é desnecessária.

\section{(Os processos e suas séries)}

A consideração dessa condição documental como característica marcante da obra moderna é um dos desdobramentos possíveis que podem ser extraídos das reflexões de Benjamin no controvertido ensaio "A obra de arte na era de sua reprodutibilidade técnica” (1936). Entretanto, para além de se considerar a extração manual ou mecânica da obra como um condicionante, com um ou outro valor, deduz-se das cogitações de Benjamin a necessidade da atenção à qualidade serial de muitos dos processos artísticos modernos em antítese à tradicional e "aurática" unicidade da obra de arte.

É essa condição produtiva básica, aqui considerada, que contradita e, do ponto de vista deste estudo, diminui consideravelmente o real alcance dos métodos investigativos do formalismo - não obstante todo rigor e todas as minúcias de certos intérpretes, que operam concentrados única e exclusivamente na análise supostamente imanente, mas que, na verdade crua, exerce-se isolada e descontextualizada da obra, tal como esta se apresenta no ambiente neutro do museu ou da coleção. Há nessa perspectiva que positiva e absolutiza a obra, convertendo-a numa espécie de pequeno universo encapsulado e auto-referido, a premissa implícita de que a obra, tal uma cifra secreta, encerre em si mesma a verdade do todo; verdade esta de que a arte se faria supostamente portadora, como uma 
7. "Um problema central do materialismo histórico que finalmente deverá ser observado: se a compreensão marxista da história tem de ser adquirida necessariamente ao preço da visibilidade (Anschaulichkeit) da própria história. Ou: por qual caminho é possível unir visibilidade intensificada e aplicação do método marxista? $\mathrm{O}$ primeiro passo deste caminho será assumir o princípio da montagem na história. Erigir, assim, as grandes construções a partir de minúsculos elementos confeccionados de modo nítido e preciso. E mesmo descobrir, na análise do pequeno momento particular, o cristal do espécie de relíquia auto-suficiente da unidade e da autotransparência da razão, nos termos de certa concepção de racionalidade que, no fundo, é mitológica e mística.

Para a perspectiva ora desenvolvida, a obra em estado de isolamento carece efetivamente de objetividade, se não for remetida ao seu contexto próprio, o que não impede que, historicamente, no diálogo ou confronto de uma obra com outra, aspectos antes desapercebidos ou latentes sobressaiam e ganhem novo peso, em função de rearticulações num ou noutro sentido, eventualmente produzidas, tal numa montagem, pela interpretação.

\section{(Estratégia crítica)}

A fim de reabrir a leitura de algumas obras modernas, as investigações em pauta priorizam: a remissão da obra ao contexto histórico de origem e a busca, mediante a montagem de diálogos ou confrontos com elementos variados do seu contexto de produção, dos aspectos ignorados nessas obras pelo formalismo; procuram assim estabelecer um confronto explícito com as interpretações formalistas.

Desse modo, é necessário certas vezes contornar ou adiar a interpelação direta da obra visada, porque se deve passar pela construção de um espaço histórico, até eventualmente nele se reencontrar o trabalho em questão, mediante a reposição do confronto com algum outro termo do seu contexto.

De acordo com o propósito de reinscrever a obra no seu chão histórico, rearticulado pela pesquisa "a partir de minúsculos elementos confeccionados de modo nítido e preciso", como indica Benjamin 7 , o trabalho presente consiste, em grande parte, numa montagem que recolhe e integra resultados de análises e depoimentos de diferentes fontes e procedências. Umas e outras são incluídas num encadeamento que tem como objetivo precípuo explicitar possibilidades de rediscussão da arte moderna, relegadas pelo formalismo.

\section{SUMÁRIO: DO TRAJETO DESTA INVESTIGAÇÃO}

Para além da recapitulação crítica dos principais tópicos da interpretação formalista dos artistas focalizados, o trabalho esboça novas aproximações interpretativas. Assim, examina-se a reinvenção do realismo por Manet, a partir da insuficiência manifesta dos parâmetros do realismo precedente, protagonizado por Courbet. A proposição de Baudelaire, demandando a combinação da experiência individual da transitoriedade e do instante, que é caracteristicamente moderna, com o teor duradouro e universalizante da reflexão, sinaliza a estratégia de Manet de atualização do realismo, que situará o horizonte para a redefinição dessa perspectiva, não mais em função da veracidade estereométrica, mas da verossimilhança temporal, como apreensão do flagrante. 
Propõe-se a seguir o confronto da pintura de Manet com o impressionismo e a verificação da tese de que as obras de Cézanne e Van Gogh desenvolveram uma espécie nova de realismo, na linha de Manet, assentada na documentação autêntica da atualidade do fazer pessoal - que reage à abstração crescente das formas sociais de trabalho - e na explicitação da trama da pintura, crescentemente empenhada em aliar concretude e reflexão, ou seja, em expor o engendramento concreto da consciência, assim como da pintura, como condição de acesso ao mundo do sujeito, posto em termos fenomênicos.

A investigação aborda o cubismo a partir da hipótese de que este tenha se constituído como síntese crítica e dialética diante do novo modo de produção industrial. A impossibilidade de compreensão de um trabalho cubista, tomado isoladamente ou independentemente dos outros que fazem parte da mesma série produtiva, coloca a necessidade da análise estética enfrentar os novos princípios produtivos: a "forma aberta" ou o "princípio da descontinuidade", a produção simultânea, a permutação das partes e a combinação de elementos ostensivamente não relacionados entre si. Nesse sentido, a investigação do cubismo apresenta também novas dificuldades para a interpretação, exigindo uma compreensão efetiva da natureza da série e levando o intérprete a adotar uma postura não contemplativa, mas ativa e intervencionista como num processo de montagem.

A seguir, a investigação enfoca o surgimento do expressionismo abstrato e a obra de Pollock em especial. Sobressaem aí os novos condicionantes gerais da arte moderna, ligados ao contexto propriamente norte-americano e às trágicas experiências históricas que levam à II Guerra Mundial e ao seu desenlace, que revertem o componente otimista do cubismo, e das quais emerge o expressionismo abstrato. Entram em cogitação como fatores originários dessa pintura a releitura pictórica da colagem e da construção, a releitura crítica da pintura surrealista e ainda e principalmente elementos extrínsecos à pintura e próprios à superprodução da economia norte-americana.

Salienta-se a redefinição da idéia de forma a partir de fatores quantitativos, na obra de Pollock, no imediato pós-guerra, o que implica uma espécie de pintura que, em ruptura com a idéia albertiana do quadro como janela, consiste na sobreposição de camadas e requer a participação ativa do corpo na produção como na observação da arte, segundo termos cinestésicos que foram lançados, décadas antes, pela escultura-construção cubista.

Destaca-se ainda a assunção por Pollock, a partir do acerto firmado, em 1943, com a galeria de Peggy Guggenheim, do modelo simbólico do contrato como ordenação descontínua dos interesses, como novo paradigma para a arte em lugar daquele da natureza e, em conseqüência, a assimilação, na esteira de Duchamp, da idéia da circulação ou do modo de difusão da arte, como fator intrínseco à produção. A hipótese deste estudo é a de que, uma vez finda toda a possibilidade de diálogo vivo com a natureza, ou da funcionalidade histórica do acontecimento total (Totalgeschehen).

Romper, portanto, com o naturalismo

histórico vulgar.

Compreender a

construção da história enquanto tal. $\mathrm{Na}$

estrutura do comentário. Detritos da história".

BENJAMIN, Walter.

O trabalho das passagens. n. 2, 6 .

Trad. Sonia C. N.

Ferrari. Cadernos de

filosofía alemã, 3, São Paulo, Departamento de Filosofia da USP, FFLCH-USP, 1997, p. 75

8. O primeiro capítulo da tese, que dá seguimento ao presente texto, já teve alguns extratos ou artigos derivados publicados nas revistas Arte e ensaio, Rio de Janeiro, PPGAV-EBA-UFRJ, n. 8, p. 102-11, 2001; Mais-valia, São Paulo, n. 1, p. 88-95, nov. 2007; na ARS, n. 10, p. 50-60, $2007 \mathrm{e}$ originou o livro Manet: uma mulher de negócios, um almoço no parque $e$ um bar. Rio de Janeiro: Zahar, 2007. (Coleção Arte+). 
"gênio" concebido como natureza, a arte de Pollock, sendo a do gênio redefinido segundo a configuração social existente, como força contratada, já opera, tal como a arte de Duchamp, de corpo inteiro no "mundo desencantado".

Por fim, a investigação focaliza a obra de Mark Rothko. Em face da morte anunciada da "pintura de cavalete" e do sujeito pictórico artesanal, que foi descortinada por Tarabukin, em 1923, na URSS (portanto, vinte e cinco anos antes de Clement Greenberg [1909-1994] anunciar a crise da produção de cavalete, nos EUA do pós-guerra), a dimensão intrinsecamente histórica e reflexiva da pintura de Rothko leva-a a promover a releitura crítica incessante e cerrada das questões nucleares da tradição pictórica: a transparência, a luminosidade, o tonalismo, a contemplação, a unidade orgânica da obra etc. A exigência materialista da pintura de Rothko o conduz à busca das condições de exposição e difusão da pintura, as mais próximas possíveis daquelas verificadas na produção, e à postulação de uma refuncionalização da pintura, para a qual o teatro e a arquitetura exercerão papel paradigmático.

O trabalho examina a hipótese da chamada "Capela Rothko", na Menil Foundation de Houston, assinalar o corolário desse projeto histórico-pictórico. A capela também representaria, nesse sentido, o desaguadouro do projeto geral do expressionismo abstrato, de superar a "pintura de cavalete" e de levar a pintura a exercer, sob a forma do mural e das obras de grande formato, um estatuto simbólico cívico, além dos limites esgotados do quadro.

Luiz Renato Martins é professor do Departamento de Artes Plásticas da Escola de Comunicações e Artes da Universidade de São Paulo. 


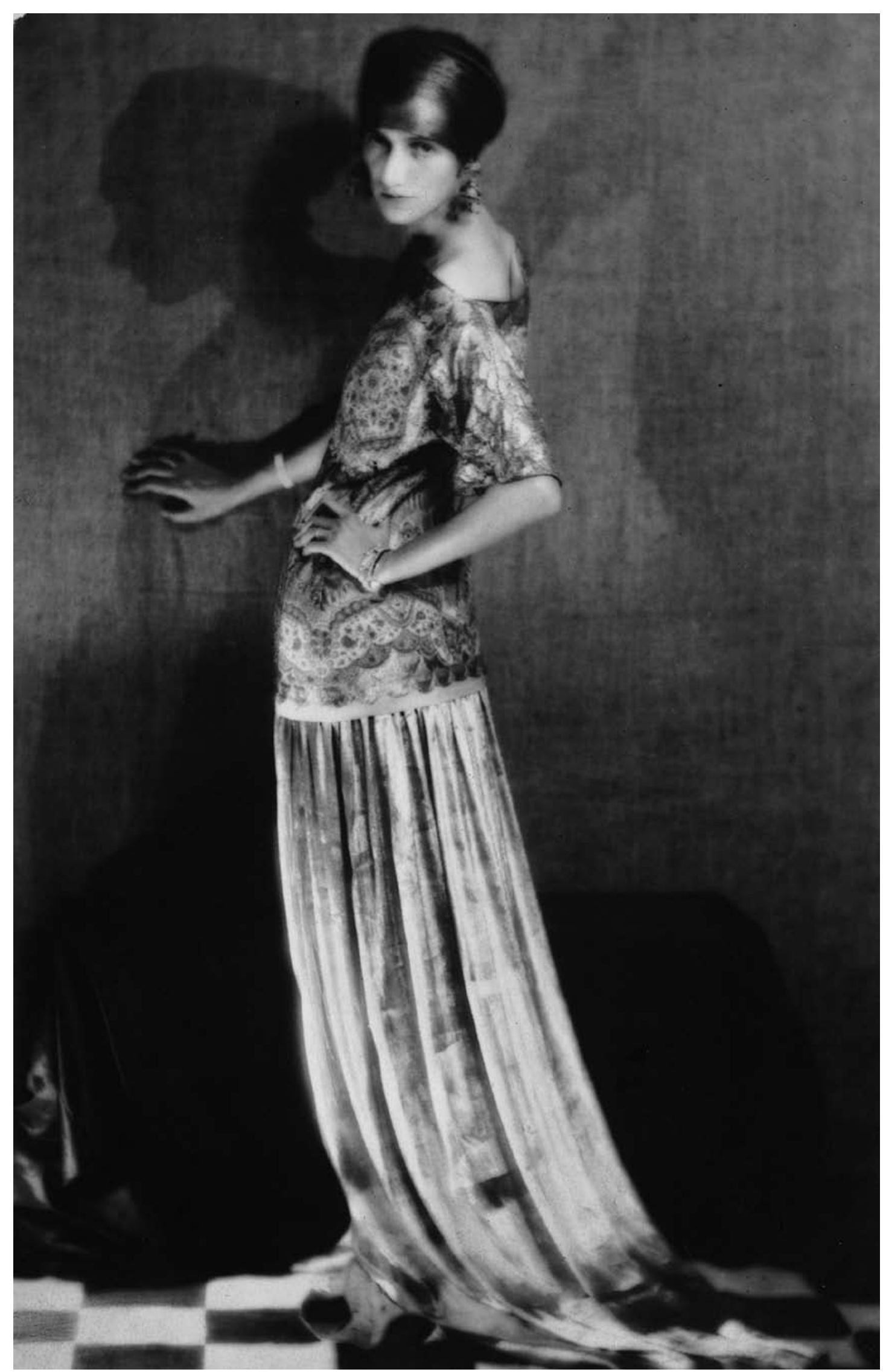

